\section{The effects of pinealectomy on the activity levels in rats}

\section{N. R. REMLEY, D. M. BRYON, and F. R. WILSON, Texas Christian University, Fort Worth, Tex. 76129}

The purpose of this experiment was to investigate the effects of pinealectomy on the activity of rats maintained with a light-dark cycle of illumination and then abruptly changed to the condition of continuous illumination. The analysis of the data revealed that pinealectomy had no effect on the activity cycle under the condition of light-dark illumination nor continuous illumination.

It is known that the pineal complex of lower vertebrates frequently includes eyelike and photosensory regions (van de Kamer, 1965). Stebbins \& Eakin (1958) have suggested that the pineal acts as a participant in the regulation of the locomotor activity of lower vertebrates in relation to illumination.

In contrast to the pineal complex of lower vertebrates, the mammalian pineal is a gland-like organ without photoreceptors or evidence of direct response to light (Quay, 1965a). Nevertheless, it has been demonstrated that certain metabolic activities in the mammalian pineal organ exhibit daily fluctuations that are closely associated with changes in the environmental ligh ting. Quay shown that there is a definite circadian rhythm in serotonin content of the rat highest at midday and then drops to a nocturnal low following the onset of darkness. It has been reported that this serotonin rhythm is affected by alternations of the light-dark cycle (Snyder, 1965b).

The current belief is that visual information concerning illumination is transferred to the mammalian pineal organ by the nervous system (Axelrod \& Wurtman, 1965; Moore, Heller, Wurtman, \& Axelrod, 1967). At the same time, there has been speculation that the mammalian pineal organ with its presumed endocrine secretion somehow participates in the regulatory system which controls many biological functions in relation to changes in the relative amount of daylight (Grossman, 1967).

Munn (1950) reports that the activity of the rat is a function of illumination with the rat being primarily nocturnal and having a peak activity period around midnight. Several studies have been reported which have attempted to investigate the hypothesis that the pineal organ participates in the (1963) and Snyder (1965a) have both pineal. The amount of pineal serotonin is regulation of the activity cycle in rats by examining the running wheel activity of pinealectomized rats under varying conditions of environmental illumination.

Quay (1965b) has shown that the running unabated in pinealectomized animals in response to continuous illumination. Also, in a later study, Quay (1968) showed that the response of pinealectomized rats to the reduction of the intensity of continuous illumination did not alter the running wheel activity; however, Peacock, Hodge, \& Thomas (1966) have demonstrated that the frequency of activity in the rat tends to spread out when the period of continuous illumination is short ( $2-4$ weeks). Thus, it remained to be shown what the effects of pinealectomy are on the activity of the rat maintained with a light-dark cycle of illumination.

This present experiment was designed primarily to test the hypothesis that the rat pineal organ participates in the regulation of running activity in rats as a function of a light-dark cycle of illumination. This experiment also examined the follow-up effects of abruptly changing the light-dark cycle to one of continuous illumination.

\section{SUBJECTS}

Twelve naive male albino rats of the Sprague-Dawley strain served as Ss. Ss were 5-6 months of age at the time of surgery. wheel activity in adult male rats continued

\section{APPARATUS}

Six Wahmann activity wheels with attached cages were used. The activity wheels were equated for friction and found to be essentially the same. The six cages were arranged on a table in such a manner that no $S$ would have visual contact with any other S.

A room approximately $6 \times 15 \mathrm{ft}$ and painted flat black served as the experimental area. The single overhead source of illumination was provided by two $4-\mathrm{ft}$ florescent light bulbs.

\section{PROCEDURE}

All Ss were obtained from a colony maintained under continuous illumination. The $12 \mathrm{Ss}$ were divided into two groups of 6 each. In each group, two Ss served as controls; two received sham-operations (complete surgical procedure but with the pineal organ left intact); and two were pinealectomized. All animals were maintained on ad lib food and water throughout the experiment.

The first group was returned to the colony following surgery and allowed a recovery period of 8 days. After the recovery period, the first group of Ss was brought to the experimental area and randomly assigned to the activity wheels. On Day 1, the experimental area was illuminated for a period of $12 \mathrm{~h}$, followed by a 12-h period of darkness. This 12 -h light-dark

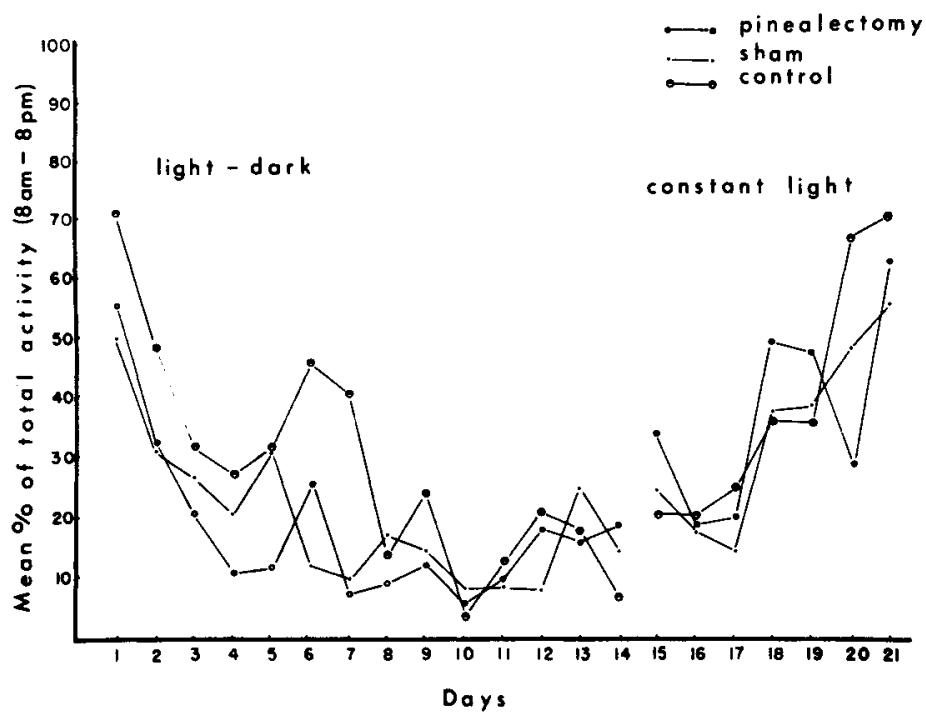

Fig. 1. The effects of pinealectomy on running wheel activity under conditions of a 12-h light-dark cycle and continuous illumination. 
cycle was maintained for 14 days. Recordings were taken from the activity counters twice daily at 8:00 a.m., when the lights were turned on, and 8:00 p.m., when the lights were turned off.

On Day 15, the 12-h light-dark cycle was discontinued. The $S s$ remained in the experimental area under the condition of continuous illumination for 7 days. Recordings were taken from the activity counters twice daily at 8:00 a.m. and 8:00 p.m. during this period.

On Day 22, the Ss were removed from the experimental area and returned to the colony. The sham-operated and pinealectomized Ss were profused, and a gross inspection of the brains was performed to evaluate the operative procedures.

The second-group Ss were allowed a surgical recovery period of 25 days before being placed in the experimental area. The experimental procedure followed for the second group of Ss was the same as that for the first group.

\section{RESULTS}

For purposes of analysis, the data was transformed to the per cent of total activity recorded between the hours of 8:00 a.m. and 8:00 p.m. In the first phase of the study, this was the activity recorded during the light portion of the light-dark cycle. Post mortem inspection of the Ss' brains revealed that the pineal organ was only partially removed from one animal. Therefore, only the data from the three completely pinealectomized animals were included in the analysis.

The analysis of the data recorded during the light-dark cycle revealed no statistically significant differences between groups ( $F<1.00)$ and no statistically significant interaction $(F<1.00)$. The effect of days was statistically significant $(\mathrm{p}<.001)$ and is probably a reflection of adaptation.

The analysis of the data recorded during continuous light also revealed no statistically significant differences between groups $(F<1.00)$ and no statistically significant interaction $(F=1.56, \mathrm{df}=12 / 48)$. The effect of days was again statistically significant $(\mathrm{p}<.001)$. These data are graphically illustrated in Fig. 1.

\section{DISCUSSION}

Although the present study used a different response measure of activity in the running wheel from the one employed by Quay (1968), the results of this study agree with Quay's findings in that pinealectomy does not alter gross locomotor activity.

Since Quay (1963) and Snyder (1965b) have reported that the serotonin content of the rat pineal is rhythmical and related to the level of environmental illumination, the results of the present study also suggest that the serotonin change is apparently not necessary in regulating the change in gross locomotor activity as a function of varying conditions of illumination.

Although Quay (1968) and the present authors failed to demonstrate any significant effects of pinealectomy on measures of locomotor activity, it is possible that other measures of activity could reveal effects not shown by the running wheel. Since it has been reported that pinealectomy results in changes in the genital system (Crosby, Humphrey, \& Lauer, 1962), it is also possible that the behavioral effects of pinealectomy may be evidenced in changes in specific behaviors, i.e. sexual behavior, rather than in changes of general activity levels.

\section{REFERENCES}

AXELROD, J., \& WURTMAN, R. J. The pineal gland. Scientific American, 1965. 213, 50-60. CROSBY, E. C., HUMPHREY, T., \& LAUER, E. W. Correlative anatomy of the nervous system. New York: The Macmillan Co., 1962. GROSSMAN, S. P. A textbook of physiological psychology. New York: John Wiley \& Sons, 1967.

MOORE, R. Y., HELLER, A., WURTMAN, R. J., \& AXELROD, J. Visual Pathway mediating pineal response to environmental light. Science, $1967,155,220-223$.

MUNN, N. L. Handbook of psychological research on the rat. New York: Houghton Mifflin, 1950.

PEACOCK, L. J., HODGE, M. H., \& THOMAS, R. $K$. Ultrasonic measurement and automatic analysis of general activity in the rat. Joumal of Comparative \& Phy siological Psychology, 1966, 62, 284-288.

QUAY, W. B. Circadian thythm in rat pineal serotonin and its modifications by estrous cycle and photoperiod. General \& Comparative Endocrinology, 1963, 3, 473-479.

QUAY, W. B. Histological structure and cy tology of the pineal organ in birds and mammals. Progress in Brain Research, 1965a, 10,49-84.

QUAY, W. B. Photic relations and experimental dissociation of circadian rhythms in pineal composition and running activity in rats. Photochemistry \& Photobiology, 1965b, 4, 425-432.

QUAY, W. B. Individuation and lack of pineal effect in the rat's circadian locomotor rhy thm. Physiology \& Behavior, 1968, 3, 109-118.

SNYDER, S. H. Circadian rhythm in pineal serotonin: Effect of MAO inhibition and reserpine. Science, 1965a, 149, 542-544.

SNYDER, S. H. Control of the circadian rhy thm in serotonin content of the rat pineal gland. Proceedings of the National Academy of Sciences, 1965b, 53, 301-305.

STEBBINS, R.C., \& EAKIN, R. M. The role of the "third eye" in reptilian behavior. American Museum Novitates, 1958, No. 1870.

van de KAMER, J. C. Histological structure and cytology of the pineal complex in fishes, amphibians, and reptiles. Progress in Brain Research, 1965, 10,30-48. 